\title{
Moléstias em tomateiro cultivado em estufas plásticas em quatro municípios da região central do Rio Grande do Sul, Brasil ${ }^{1}$
}

\author{
Diseases on tomato cultivated in plastic greenhouses in four locations in the central \\ region of Rio Grande do Sul, Brazil
}

Elena Blume $^{1}$ Alicia Susana Aquino Jara ${ }^{2}$

RESUMO

Moléstias podem atacar severamente hortaliças cultivadas em cultivos protegidos e, para o manejo integrado dessas moléstias, o conhecimento das condições climáticas que favorecem sua incidência nesses cultivos é fundamental. $O$ trabalho teve o objetivo de identificar as moléstias em tomateiro cultivado em estufas plásticas em quatro municípios na região central do Rio Grande do Sul e as condições de temperatura e umidade relativa $(U R)$ do ar nas quais elas ocorrem. $O$ estudo foi realizado nos municípios de São Pedro do Sul, São Sepé, Ivorá e Santa Maria (RS), no período de março a outubro de 1998. A temperatura e umidade relativa do ar foram medidas diariamente com um psicrômetro. As moléstias observadas e sua incidência máxima foram: requeima (Phytophthora infestans): 100,0\%, pinta-preta (Alternaria solani): 98,1\%, mofo cinzento (Botrytis cinerea): $55,4 \%$, cladosporiose (Cladosporuim fulvum): $48,9 \%$, septoriose (Septoria lycopersici): 37,5\%, talo-oco (Erwinia spp.): $33,0 \%$, murcha de fusarium (Fusarium oxysporum $f$. $s p$. lycopersici): $8,4 \%$ e podridão de esclerotínia (Sclerotinia sclerotiorum): $1,3 \%$. Valores de UR superiores a $80 \%$, de maneira geral, aumentaram a incidência das moléstias, em sua maioria de origem fúngica. A incidência de moléstias varia entre municípios de uma mesma região climática de acordo com os fatores meteorológicos e práticas de manejo da cultura.

Palavras-chave: ambiente protegido, fatores meteorológicos, doenças, fungos, manejo cultural.

\section{ABSTRACT}

Fungal and bacterial diseases can severely damage vegetables cultivated in commercial greenhouses and, for integrated disease management, knowing the environmental conditions that favor the occurrence of diseases is fundamental. The objective of this work was to identify the diseases in tomato cultivated in plastic greenhouses in four locations in Rio Grande do Sul and the temperature and relative humidity favoring plant diseases. This study was done in four greenhouses, cropped to tomato, located in São Pedro do Sul, São Sepé, Ivorá, and Santa Maria (RS-Brazil), from March to October of 1998. The air temperature and the relative humidity inside the greenhouses were measured daily with a psicrometer. The diseases identified and their maximum incidence were: late blight (Phytophthora infestans): 100,0\%, early blight (Alternaria solani): $98,1 \%$, gray mold (Botrytis cinerea): 55,4\%, leaf mold (Cladosporuim fulvum): $48,9 \%$, leaf spot (Septoria lycopersici): $37,5 \%$, soft rot (Erwinia spp.): 33,0\%, fusarium wilt (Fusarium oxysporum $f$. sp. lycopersici): $8,4 \%$, and watery soft rot (Sclerotinia sclerotiorum): 1,3\%. Air relative humidity greater than $80 \%$, in general, increased disease incidence, which were predominantely caused by fungi. The disease incidence on tomato varied among locations in the same climatic region due to variations in meteorological conditions and crop management practices.

Key words: modified environment, meteorological condition, fungy, crop management.

\section{INTRODUÇÃO}

Algumas espécies olerícolas são atacadas por um maior número de patógenos, os quais são capazes de causar moléstias com severidade elevada, como é o caso do tomateiro.

Condições de temperatura e umidade peculiares aos ambientes protegidos modificam o comportamento das moléstias em relação àquele observado no campo. Em estufas, a umidade ambiental é manejada mediante a ventilação lateral (ROBLEDO \& MARTIN, 1981).

Atualmente a moléstia fúngica mais importante em tomateiro no Brasil é a pinta-preta causada por Alternaria solani (Ell. \& Martin) Jones

${ }^{1}$ Parte da dissertação de mestrado do segundo autor, submetida ao Programa de Pós-graduação em Agronomia, Universidade Federal de Santa Maria ( UFSM).

${ }^{2}$ Engenheiro Agrônomo, MSc, PhD, Professor Adjunto, Departamento de Defesa Fitossanitária, Centro de Ciências Rurais, UFSM. 97105-900 Santa Maria, RS. E-mail: eblume@ccr.ufsm.br.

${ }^{3}$ Engenheiro Agrônomo, MSc, Profesor, Facultad de Ciencias Agrarias, UNA, Casilla de Correo 1618, Asunción, Paraguay. 
\& Grout, sendo favorecida por condições de alta temperatura e umidade (LOPES \& SANTOS, 1994). Outro agente patogênico bastante destrutivo no tomateiro é Phytophthora infestans (Mont) De Bary, responsável pela requeima, moléstia que afeta todos os órgãos aéreos da planta. Esse patógeno necessita de alta umidade e temperatura em torno de $20^{\circ} \mathrm{C}$ (KUROZAWA \& PAVAN, 1997). OLIVEIRA (1994) verificou aumento da infecção de requeima com médias de temperatura máxima de $24,9^{\circ} \mathrm{C}$ e mínima de $13,5^{\circ} \mathrm{C}$ e UR de $77,5 \%$.

ELMER \& FERRANDINO (1995) relatam que a temperatura foi a variável climática mais importante no desenvolvimento da septoriose causada pelo fungo Septoria lycopersici Speg.. Temperaturas entre 20 e $25^{\circ} \mathrm{C}$ favorecem a moléstia, contribuindo para produzir grande quantidade de inóculo.

A moléstia causada pelo fungo Fusarium oxysporum f. sp. lycopersici (Sacc.) Snyder \& Hansen, conhecida como murcha de fusarium, é favorecida por temperaturas que variam de 21 a $33^{\circ} \mathrm{C}$, tendo como condições ótimas temperatura ao redor de $28^{\circ} \mathrm{C}$ e alta umidade (KUROZAWA \& PAVAN, 1997).

O talo-oco, causado pela bactéria Erwinia sp., é uma moléstia característica do caule do tomateiro. A moléstia causa grandes perdas, durante verões chuvosos ou em cultivos em que há irrigação em excesso (LOPES \& QUEZADO-SOARES, 1997). Todos os sintomas característicos da moléstia foram observados com temperatura de $20^{\circ} \mathrm{C}$ e UR do ar de $100 \%$, em tomateiros com 4 a 5 meses de idade, em estufa comercial (MALATHRAKIS \& GOUMAS, 1988).

Para a adoção de um manejo integrado de moléstias em hortaliças, estudos sobre a incidência de moléstias e sua relação com fatores meteorológicos, particularmente temperatura e UR do ar, são necessários.

Este trabalho teve o objetivo de identificar as moléstias em tomateiro cultivado em estufas plásticas em quatro municípios na região central do Rio Grande do Sul e as condições de temperatura e umidade relativa do ar nas quais elas ocorrem.

\section{MATERIAL E MÉTODOS}

O estudo foi conduzido em três estufas plásticas comerciais localizadas nos municípios de São Pedro do Sul (latitude: $29^{\circ} 37^{\prime} \mathrm{S}$, longitude: $54^{\circ} \mathrm{W}$, altitude: $160,0 \mathrm{~m}$ ), São Sepé (latitude: $30^{\circ} 10^{\prime} \mathrm{S}$, longitude: $53^{\circ} 33^{\prime} \mathrm{W}$, altitude: $150,0 \mathrm{~m}$ ), Ivorá (latitude: $29^{\circ} 30^{\prime} \mathrm{N}$, longitude: $54^{\circ} 25^{\prime} \mathrm{W}$, altitude: $200,0 \mathrm{~m}$ ) e em uma estufa utilizada em pesquisa em Santa Maria (latitude: $29^{\circ} 43^{\prime} \mathrm{S}$, longitude: $53^{\circ} 42^{\prime} \mathrm{W}$, altitude: 95,0m), no RS, no período de março a outubro de 1998.

Em São Pedro do Sul e Ivorá, foi utilizada a cultivar Ágora, em São Sepé, a cultivar Carmem e, em Santa Maria, a cultivar Lenor. Essas cultivares são híbridos tipo salada, sendo que as duas primeiras apresentam hábito de crescimento indeterminado e a última crescimento determinado. Em São Pedro do Sul, São Sepé e Santa Maria, o espaçamento entre fileiras foi de $1,0 \mathrm{~m}$ e entre plantas $0,30 \mathrm{~m}$, enquanto em Ivorá o espaçamento entre fileiras foi de $0,80 \mathrm{~m} \mathrm{e}$ entre plantas de $0,35 \mathrm{~m}$. As estufas comerciais continham oito fileiras e a estufa para pesquisa três fileiras de tomateiro com comprimentos variados $(25,0$ a 50,0m). Nessa última, havia ainda três fileiras de meloeiro e duas de feijoeiro-de-vagem.

As práticas culturais adotadas foram aquelas normalmente empregadas no cultivo de tomateiro em estufa plástica. Com exceção da estufa de Santa Maria, pulverizações com fungicidas e retirada de folhas velhas com sintomas foram realizadas, sempre que julgadas necessárias, pelos produtores. Essas práticas afetaram o desenvolvimento dos patógenos e permitiram à cultura completar o seu ciclo.

Em intervalos de 10 a 30 dias, nas estufas comerciais, e 2 dias na estufa para pesquisa, foram realizadas inspeções para determinar a incidência e a severidade das moléstias. A incidência foi determinada em 462, 632, 246 e 105 plantas, em São Pedro do Sul, São Sepé, Ivorá e Santa Maria, respectivamente, ou seja, todas plantas das quatro fileiras, nas estufas comerciais, e das duas fileiras centrais na estufa para pesquisa. Sessenta plantas, nas estufas comerciais, e 32 plantas, na estufa para pesquisa, foram marcadas para acompanhamento da severidade das moléstias.

Uma semana antes do início das inspeções, foi instalado um psicrômetro, a 1,50 m de altura, no centro de cada estufa, nos quatro municípios, para registro diário da temperatura e da UR do ar.

A diagnose das moléstias foi realizada com base nos sintomas típicos de cada moléstia. Em caso de dúvida quanto a algum sintoma, amostras foram transportadas ao Laboratório de Fitopatologia do Departamento de Defesa Fitossanitária da UFSM para análise e diagnose do agente causal.

\section{RESULTADOS E DISCUSSÃO}

As moléstias observadas em plantas cultivadas nas estufas foram, em sua maioria, de origem fúngica. Na região de abrangência de Santa 
Maria, HEINEN et al (1996) também verificaram predominância de moléstias fúngicas em estufas abrigando hortaliças.

As moléstias observadas nos municípios de São Pedro do Sul, São Sepé, Ivorá e Santa Maria constam nas tabelas 1, 2, 3 e 4, respectivamente. Em várias inspeções, nas estufas comerciais, observou-se redução ou eliminação de algumas moléstias devido à remoção, pelos produtores, das folhas mais velhas das plantas, nas quais se encontrava a maioria dos sintomas. Devido à essa prática e à utilização de fungicidas, a severidade das moléstias policíclicas, nessas estufas, não ultrapassou $5 \%$.

A moléstia pinta-preta (Alternaria solani (Ell. \& Martin) Jones \& Grout) foi observada em todos os municípios, exceto em Santa Maria. As condições para o aparecimento da pinta-preta são alta temperatura e alta UR do ar (DOROZHIKIN \& IVANYUK, 1980; OLIVEIRA, 1994; LOPES \& SANTOS, 1994). Neste levantamento, com o aumento da UR para valores superiores a $80 \%$, houve um grande incremento na incidência da moléstia, aumentando em 53 pontos percentuais (passou de 39,7 para $92,7 \%$ ) em São Pedro do Sul e em 68,8 pontos percentuais em São Sepé. No final do cultivo, a incidência atingiu 97\% em São Pedro do Sul (Tabela 1) e 98\% em São Sepé (Tabela 2), mesmo com a retirada de folhas velhas e a aplicação dos fungicidas Chlorotalonil, Metalaxyl e Iprodione. Já em Ivorá (Tabela 3), a diminuição da UR para $66,2 \%$, no período, foi acompanhada de um aumento de $59 \%$ na incidência da moléstia. A retirada de folhas velhas e a aplicação de Tebuconazole, Iprodione e Benomyl controlaram a moléstia nessa estufa. Provavelmente, nos dois primeiros municípios, a alta densidade de plantas com folhagem abundante e a presença de fonte de inóculo nas plantas de tomateiro senescentes das estufas adjacentes, em que não se fazia nenhum tipo de tratamento químico e apresentavam sintomas de pintapreta, tenham propiciado esse aumento na incidência. Além disso, a localização das estufas na direção predominante do vento facilitou a dispersão dos esporos do fungo entre estufas.

A septoriose (Septoria lycopersici Speg.), presente somente em São Pedro do Sul (Tabela 1), apresentou $37,5 \%$ de incidência, com médias de temperatura de $27,3^{\circ} \mathrm{C}$ e UR de $63,3 \%$. ELMER \& FERRANDINO (1995) relatam que temperaturas ótimas para o desenvolvimento da septoriose em tomateiro estão entre 20 e $25^{\circ} \mathrm{C}$ e que esse fator é mais determinante que a UR para o exitoso desenvolvimento da moléstia. Os mesmos autores alegam que as feridas feitas pelo roçar entre as folhas e pelo homem facilitam a entrada do patógeno nas plantas favorecendo o desenvolvimento da infecção, em períodos de baixa umidade, como o observado neste levantamento. A retirada de folhas com sintomas e a pulverização com Cholorothalonil e Metalaxyl controlaram a moléstia.

O mofo cinzento (Botrytis cinerea Pers) foi observado nas estufas de São Pedro do Sul (Tabela 1) e Ivorá (Tabela 3), sendo que, nessa última, a incidência foi crescente com o aumento da

Tabela 1 - Incidência de pinta-preta, septoriose, mofo cinzento e podridão de esclerotínia em tomateiro, e temperatura e umidade relativa (UR) em estufa plástica comercial no município de São Pedro do Sul. Santa Maria, RS, 1998.

\begin{tabular}{|c|c|c|c|c|c|c|}
\hline \multirow{2}{*}{$\begin{array}{l}\text { Data de Inspeção } \\
\text { (1998) }\end{array}$} & \multicolumn{4}{|c|}{ Incidência (\%) } & \multirow{2}{*}{$\begin{array}{l}\text { Temp. } * * \\
\left({ }^{\circ} \mathrm{C}\right)\end{array}$} & \multirow{2}{*}{$\begin{array}{l}\mathrm{UR} * * \\
(\%)\end{array}$} \\
\hline & Pinta-preta & Septoriose & Mofo cinzento & Podridão de esclerotínia & & \\
\hline Maio, 06 (a)* & 39,7 & 37,5 & 0,0 & 0,0 & 27,3 & 63,3 \\
\hline Maio, 27 (b) & 92,7 & 0,0 & 0,0 & 0,0 & 26,1 & 82,6 \\
\hline Junho, 19 (c) & 85,0 & 0,0 & 0,0 & 0,0 & 20,2 & 88,6 \\
\hline Julho, 08 & 80,1 & 0,0 & 0,0 & 0,0 & 22,6 & 85,8 \\
\hline Julho, 29 (d) & 90,0 & 0,0 & 6,3 & 0,0 & 21,7 & 80,8 \\
\hline Agosto, 19 (e) & 90,2 & 0,0 & 0,0 & 0,3 & 21,1 & 81,2 \\
\hline Setembro, 09 (f) & 90,5 & 0,0 & 0,0 & 0,0 & 21,6 & 85,8 \\
\hline Setembro, 16 & 97,0 & 0,0 & 0,0 & 0,0 & 23,2 & 76,1 \\
\hline
\end{tabular}

*Pulverizações realizadas no período entre inspeções:

(a) Chlorotalonil

(b) Chlorothalonil e Metalaxyl

(c) Chlorothalonil, Mancozeb, Benomyl e Iprodione

(d) Mancozeb e Benomyl

(e) Mancozeb, Chlorothalonil e Iprodione

(f) Chlorothalonil

**Dados registrados às $15 \mathrm{~h}$, representando a média do período entre inspeções. 
Tabela 2 - Incidência de cladosporiose, pinta-preta, requeima e talo-oco em tomateiro, e temperatura e UR em estufa plástica comercial no município de São Sepé. Santa Maria, RS, 1998.

\begin{tabular}{lccccc}
\hline $\begin{array}{l}\text { Data de Inspeção } \\
(1998)\end{array}$ & Incidência (\%) & & & & $\begin{array}{c}\text { Temp. } * * \\
\left({ }^{\circ} \mathrm{C}\right)\end{array}$ \\
\cline { 2 - 5 } & Cladospo-riose & Pinta-preta & Requeima & Talo-oco & $\begin{array}{c}\text { UR } * * \\
(\%)\end{array}$ \\
\hline Abril, 24 (a)* & 48,9 & 0,0 & 0,0 & 0,0 & 22,8 \\
Junho, 04 (b) & 0,0 & 16,7 & 43,5 & 0,0 & 22,7 \\
Junho, 22 (c) & 0,0 & 85,5 & 0,0 & 0,9 & 21,5 \\
Julho, 16 (c) & 0,0 & 88,5 & 0,0 & 14,6 & 21,8 \\
Agosto, 07 (c) & 0,0 & 97,5 & 0,0 & 31,2 & 80,7 \\
Setembro, 08 & 0,0 & 98,1 & 0,0 & 33,0 & 8,7 \\
\hline
\end{tabular}

*Pulverizações realizadas no período entre inspeções:

(a) Tiofanato metílico

(b) Metalaxyl, Chlorothalonil e Iprodione

(c) Iprodione

**Dados registrados às $15 \mathrm{~h}$, representando a média do período entre inspeções.

temperatura e da UR, chegando a $55 \%$ das plantas, mesmo com a aplicação de fungicidas. O cancelamento da pulverização com fungicidas, entre as duas últimas inspeções, fez com que a incidência aumentasse em 21,9 pontos percentuais em 15 dias. No período anterior, o uso de fungicidas fez que com a incidência aumentasse em apenas 2,4 pontos percentuais em 33 dias. JARVIS (1992) relata que $\boldsymbol{B}$. cinerea precisa de uma película de água sobre os órgãos da planta para germinar. Portanto, a alta UR do ar (acima de 85\%), a escassa ventilação da estufa e a abundante folhagem das plantas, permitindo a permanência de esporos do fungo nas folhas e frutos, contribuíram para a manifestação constante da moléstia. No final do ciclo da cultura foi observada a podridão de esclerotínia (Sclerotinia sclerotiorum (Lib.) De Bary), com incidência mais elevada $(1,35 \%)$ em Ivorá (Tabela 3), quando a temperatura era de 29,2 e a UR de $87,8 \%$. Essas condições são consideradas ótimas para o desenvolvimento dessa moléstia (JONES et al., 1995).

A cladosporiose (Cladosporium fulvum Cooke) mostrou uma incidência elevada em São Sepé $(48,9 \%$ ) (Tabela 2$)$, com médias de temperatura de

Tabela 3 - Incidência de cladosporiose, pinta-preta, murcha de fusarium, mofo cinzento e podridão de esclerotínia em tomateiro, e temperatura e umidade relativa (UR) em estufa plástica comercial no município de Ivorá. Santa Maria, RS, 1998.

\begin{tabular}{|c|c|c|c|c|c|c|c|}
\hline \multirow{2}{*}{$\begin{array}{l}\text { Data de Inspeção } \\
\text { (1998) }\end{array}$} & \multirow{2}{*}{ Clados-poriose } & \multicolumn{2}{|c|}{ Incidência (\%) } & \multicolumn{2}{|c|}{ Temp.** } & \multicolumn{2}{|c|}{$\mathrm{UR} * *$} \\
\hline & & Pinta-preta & $\begin{array}{l}\text { Murcha de } \\
\text { fusarium }\end{array}$ & Mofo cinzento & $\begin{array}{l}\text { Podridão de } \\
\text { esclerotínia }\end{array}$ & $\left({ }^{\circ} \mathrm{C}\right)$ & $(\%)$ \\
\hline maio, $22(\mathrm{a})^{*}$ & 0,8 & 0,4 & 0,0 & 0,0 & 0,0 & 20,1 & 80,8 \\
\hline junho, 17 (b) & 0,0 & 59,7 & 1,6 & 0,0 & 0,0 & 22,8 & 66,2 \\
\hline julho, 07 (c) & 0,0 & 18,4 & 0,0 & 0,0 & 0,0 & 20,9 & 78,3 \\
\hline julho, 28 (d) & 0,0 & 0,0 & 0,0 & 0,8 & 0,0 & 17,2 & 87,9 \\
\hline agosto, 18 & 0,0 & 0,0 & 0,0 & 23,0 & 0,0 & 23,0 & 70,9 \\
\hline setembro,10 (e) & 0,0 & 0,0 & 7,0 & 31,1 & 0,0 & 20,8 & 90,8 \\
\hline outubro,13 (f) & 0,0 & 0,0 & 8,4 & 33,5 & 0,4 & 24,1 & 86,5 \\
\hline outubro, 28 & 0,0 & 0,0 & 0,0 & 55,4 & 1,3 & 29,2 & 87,8 \\
\hline
\end{tabular}

*Pulverizações realizadas no período entre inspeções:

(a) Tebuconazole

(b) Tebuconazole e Benomyl

(c) Tebuconazole e Iprodione

(d) Benomyl

(e) Iprodione

(f) Benomyl

**Dados registrados às $15 \mathrm{~h}$, representando a média do período entre inspeções. 
Tabela 4 - Incidência e severidade de requeima em tomateiro, e temperatura e umidade relativa (UR) em estufa plástica de pesquisa no município de Santa Maria. Santa Maria, RS, 1998.

\begin{tabular}{lcccc}
\hline & Incidência & Severidade & $\begin{array}{c}\text { Temp.** } \\
\left({ }^{\circ} \mathrm{C}\right)\end{array}$ \\
\hline Data de inspeção (1998) & & $(\%)$ & 14,7 & $\begin{array}{c}\text { UR** } \\
(\%)\end{array}$ \\
junho, 06 & 9,5 & 0,1 & 21,5 & 80,8 \\
junho, 08 & 24,7 & 5,2 & 22,4 & 79,1 \\
junho, 10 & 43,8 & 10,4 & 18,3 & 95,6 \\
junho, 12 & 56,1 & 54,6 & 16,5 & 96,4 \\
junho, 14 & 80,9 & 75,8 & 18,2 \\
junho, 16 & 100,0 & 95,0 & 91,1 \\
\hline
\end{tabular}

**Dados registrados às $15 \mathrm{~h}$, representando a média do período entre inspeções.

$22,8^{\circ} \mathrm{C}$ e de UR de $76,9 \%$, que são menores que as relatadas por MESSIAEN et al. (1995) como sendo favoráveis à moléstia. Em Ivorá (Tabela 3), a moléstia teve uma incidência baixa $(0,8 \%)$, apesar da UR mais elevada $(80,8 \%)$. A capa pulverulenta na parte abaxial das folhas de tomateiro, sintoma inicial da moléstia, não foi observada nas inspeções posteriores, provavelmente devido à pulverização com Tiofanato Metílico, que controlou a moléstia.

A requeima (Phytophthora infestans

(Mont) De Bary) foi constatada somente em uma inspeção em São Sepé (Tabela 2), com incidência de $43,5 \%$ com médias de temperatura de $22,7^{\circ} \mathrm{C}$ e de UR de 73,7\%. Essas condições têm sido consideradas pouco favoráveis ao desenvolvimento da moléstia por JONES et al. (1995), mas têm sido observadas em sua ocorrência por outros autores (AZEVEDO \& LOURENÇATTO, 1993). A moléstia foi controlada pela remoção de folhas com sintomas e pelas pulverizações com Metalaxyl. Em Santa Maria (Tabela 4), onde as condições foram as ideais (temperatura média de $18,6^{\circ} \mathrm{C}$ e UR média de $88 \%$ ) e não foram aplicados fungicidas, a incidência e a severidade da requeima atingiram $100 \%$ em um período de 10 dias. Em apenas dois dias, de 10 a 12 de junho, a severidade da moléstia aumentou 44,2 pontos percentuais com temperatura de $18,3^{\circ} \mathrm{C}$ e a UR de $96,4 \%$, condições consideradas ótimas para o progresso da moléstia (JONES et al.,1995).

A moléstia bacteriana talo-oco (Erwinia sp.), presente na estufa de São Sepé (Tabela 2), apresentou uma incidência inicial de 0,9 e final de $33,0 \%$, com médias de temperatura de $21,3^{\circ} \mathrm{C}$ e UR de $84,9 \%$. Além dessas condições favoráveis para o desenvolvimento da moléstia (MALATHRAKIS \& GOUMAS, 1987), a realização de desbrotes, quando a planta já apresentava brotos bem desenvolvidos e vigorosos, causou ferimentos maiores, os quais são portas de entrada ao patógeno e desencadeamento da infecção bacteriana.

A murcha de fusarium (Fusarium oxysporum f. sp. lycopersici Snyder \& Hansen) ocorreu em Ivorá (Tabela 3), no início do ciclo da cultura, com uma incidência baixa $(1,62 \%)$ em temperatura e UR consideradas desfavoráveis ao patógeno ( $\mathrm{UR}=66,2 \%$ ). Mesmo após a retirada das plantas doentes e as pulverizações com fungicidas, a moléstia reapareceu quando a UR era de 90,8\%.

\section{CONCLUSÕES}

As moléstias mais frequentes em tomateiro cultivado em estufas plásticas foram pinta-preta, requeima e mofo cinzento. A incidência dessas moléstias varia entre municípios de uma mesma região climática de acordo com os fatores meteorológicos e práticas de manejo da cultura. $\mathrm{O}$ fator umidade relativa do ar é o que mais afeta a incidência de moléstias em tomateiro cultivado em estufas plásticas.

\section{REFERÊNCIAS BIBLIOGRÁFICAS}

AZEVEDO, L.A.S.; LOURENÇATTO, C.A. Epidemiologia da requeima do tomate na região sudoeste do Estado de São Paulo. In: CONGRESSO BRASILEIRO DE FITOPATOLOGIA, 26., 1993, Aracajú, SE. Anais... Brasília : Fitopatologia Brasileira, 1993. V. 18, p.272.

DOROZHIKIN, N.A.; IVANYUK, V.G. Epiphytotyc of dry leaf spot of potato and tomato. Review of Plant Pathology, v.59, n.7, p.315, 1980 .

ELMER, W.H.; FERRANDINO, F.J. Influence of spore density, leaf age, temperature, and dew periods on Septoria Leaf Spot of tomato. Plant Disease, v.79, n.3, p.287-293, 1995. 
HEINEN, G. et al. Avaliação fitopatológica em estufas na Região Central do Rio Grande do Sul. In: JORNADA DE PESQUISA DA UFSM, 3., 1996, Santa Maria, RS. Anais... Santa Maria : Pró-Reitoria de Pós-graduação e Pesquisa, 1996. 833p. p.638.

JARVIS, W.R. Managing diseases in greenhouse crops. St. Paul : APS, 1992. 288p.

JONES, J.B. et al. Compendium of tomato diseases. St. Paul: APS, 1995. 73p.

KUROZAWA, C.; PAVAN, M.A. Moléstias do tomateiro. In: KIMATI, H. et al (coord.). Manual de fitopatologia. São Paulo: Ceres, 1997. V.2, cap. 64, p.690-719.

LOPES, C.A.; SANTOS, J.R.M. dos. Moléstias do tomateiro. Brasília : EMBRAPA-SPI, 1994. 61p.
LOPES, C.A.; QUEZADO-SOARES, A.M. Moléstias bacterianas das hortaliças. Brasília : EMBRAPA, 1997. 70p.

MALATHRAKIS, N.E.; GOUMAS, D.E. Bacterial soft rot of tomato in plastic greenhouses in Greece. Review of Plant Pathology, v.67, n.3, p.157-158, 1988.

MESSIAEN, C.M. et al. Enfermedades de las hortalizas. Barcelona : MUNDI-PRENSA, 1995. 576p.

OLIVEIRA, C.A. de. Incidência e severidade de moléstias em hortaliças sob condições normais de uma horta comercial em Lavras-MG. 1994. 55f. Dissertação (Mestrado em Agronomia) - Universidade Federal de Lavras.

ROBLEDo, F.P.; MARTIN, L.V. Aplicación de los plásticos en la agricultura. Madrid: Mundi-Prensa, 1981. $553 \mathrm{p}$. 